\title{
Behavioral effects of differential postoperative housing after septal lesions made in weanling rats
}

\author{
JOHN C. DALRYMPLE-ALFORD and CHRISTIAN R. KELCHE \\ Laboratoire de Neurobiologie des Comportements, Strasbourg, France
}

\begin{abstract}
Male weanling rats that received septal lesions or control operations were subsequently housed for 40 days in an enriched condition or in social isolation to allow us to evaluate the contribution of postoperative environment to recovery of behavioral function. Septal lesions produced increased ambulation, reduced rearing in an open field (initially), impaired spontaneous alternation, and impaired performance in an eight-arm radial maze. Enrichment of the postoperative environment failed to facilitate behavioral recovery of any of these lesion-induced effects. Enriched-septal rats showed a relatively greater deficit during radial arm maze testing than did isolated-septal rats. Enriched-intact rats, on the other hand, outperformed isolated-intact rats on the radial arm maze. The behavioral deficits caused by septal lesions thus resemble some of the deficits produced by fimbria-fornix and entorhinal cortex lesions, in that they are not ameliorated by postoperative enrichment. These results contrast those of previous experiments using rats with dorsal hippocampus lesions.
\end{abstract}

The speed of lesion growth, the age at the time of injury, and the subject's experiential history are three factors that often determine the behavioral outcome of central nervous system (CNS) injury (Finger \& Stein, 1982). Most of the work on experiential history has been concerned with the question of whether the level and quality of nonspecific stimulation provided by different postoperative environments influence "recovery of function" after brain damage (Dalrymple-Alford \& Kelche, 1985; Will $\&$ Eclancher, 1984). This work suggests that postoperative enrichment attenuates some of the main deficits produced by dorsal hippocampus (DH) lesions. For example, adult rats given DH lesions have made almost twice as many errors on a Hebb-Williams maze task when they were housed in social isolation than when they were housed in an enriched environment (Kelche \& Will, 1978). In rats given $\mathrm{DH}$ lesions at 30 days of age, avoidance responding during extinction was more frequent in isolated than in group-housed or enriched rats (Will \& Kelche, 1979), spontaneous alternation was impaired in isolated and group-housed rats, but was recovered in enriched rats (Will, Deluzarche, \& Kelche, 1983). Postoperative enrichment has also been found to improve the deficits seen in radial maze tasks after early $\mathrm{DH}$ lesions. Enrichment after DH lesions does not appear to affect

An abstract of this study was published in Behavioral Brain Research, in 1985 (Vol. 20, page 84). Fellowships awarded to J. C. DalrympleAlford by the Royal Society of London and the European Science Foundation are gratefully acknowledged. This research was also supported by grants from the Fondation pour la Recherche Médicale and from the C.N.R.S. (ATP No. 4780). We also thank F. Deluzarche and J.-F. Spetz for technical assistance. Requests for reprints should be sent to $C$. $R$. Kelche at the Laboratoire de Neurobiologie des Comportements, 7, rue de l'Université, 67000 Strasbourg, France. deficits in reversal learning, however (Einon, Morgan, \& Will, 1980).

Rather different results have been obtained in studies examining the effects of postoperative enrichment on recovery from damage to other portions of the septohippocampal region. The impairments in Hebb-Williams maze learning and spontaneous alternation caused by entorhinal cortex lesions, for example, are unaffected by postoperative enrichment (Will, Kelche, \& Deluzarche, 1981). More surprisingly, postoperative enrichment actually appears to exacerbate the impairment seen in radial arm maze tasks after fimbria-fornix lesions. This sharply contrasts with the results obtained with intact rats, in which enrichment improves radial arm maze performance (Kelche, Dalrymple-Alford, \& Will, 1987).

To provide further evidence on the role of differential housing in rats with lesions to septohippocampal pathways, the present experiment examined the effects of postoperative environment on behavior in rats with septal lesions. Previous work by Ahmad and Harvey (1968) and Albert, Walsh, and Longly (1985) had shown that the "septal rage syndrome" dissipates more slowly in isolated rats (but see Fass, Wrege, Greenough, \& Stein, 1980). Johnson, Spiker, and Carlson (1984) found that postweaning isolation considerably enhances social interaction (gregariousness) in rats with septal lesions made at 7 days of age. Similar results were obtained by Eclancher and Karli $(1979,1981)$, who reported increased ambulation and rearing in an open field and faster acquisition of two-way active avoidance in isolated rats as compared with group-housed rats. Although these studies did not directly compare isolated and enriched rats and were mainly concerned with reactivity, or behaviors heavily influenced by reactivity, their findings suggest that 
postoperative enrichment would have beneficial effects on other behaviors affected by septal damage. In the present experiment, we examined the effects of postoperative environment on open-field behavior, spontaneous alternation, and radial arm maze learning. These behaviors were chosen for their sensitivity to septal lesions and to establish the possible range and task-specificity of the effects of housing environment on recovery from septal damage.

\section{METHOD}

\section{Subjects}

The 36 male Long-Evans rats used in this experiment were obtained from a commercial supplier (Janvier, France) after they had been weaned at 21 days of age into large groups. The rats were received at 22 days of age and were randomly assigned to groups of 6 rats per $40 \times 26 \times 15 \mathrm{~cm}$ Makrolon cage and then, prior to surgery, randomly assigned to different treatment groups (brain state $x$ environment). The four treatment conditions and their sample sizes were enriched-control (ECon), 9; enriched-septal (ESep), 9; isolated-control (ICon), 10; isolated-septal (ISep), 8.

\section{Surgery}

At $24 \pm 1$ days of age, the rats were given either a control operation or septal lesions under clean conditions. All rats were anesthetized with Nembutal $(38 \mathrm{mg} / \mathrm{kg}$ ) after a prior injection of atropine sulfate $(2 \mathrm{mg} / \mathrm{kg})$. Septal lesions were made at two midline points by passing a $1 \mathrm{~mA}$ continuous cathodal rectified current for $20 \mathrm{sec}$ through an Epoxylite-coated stainless steel electrode, clipped at the $0.15-\mathrm{mm}$ tip. The stereotaxic lesion coordinates were 1.1 and $1.4 \mathrm{~mm}$ anterior to bregma, and $5.4 \mathrm{~mm}$ ventral to the level of the cranium at bregma. Sham-operated rats were operated upon, but had no electrode lowered into the brain. All rats were allowed 2 days of postsurgical recovery in individual metal cages $(30 \times 20 \times$ $20 \mathrm{~cm}$ ) prior to placement in their allocated postoperative housing conditions.

\section{Postoperative Environments}

The enriched and isolated environments were similar to those described by Rosenzweig and Bennett (1969). Each enriched environment housed 12 rats, including sham-operated rats, rats with septal lesions, and rats with dorsal-hippocampus or hippocampaldisconnection lesions as part of a separate experiment. The enriched environment consisted of two large wire-mesh cages $(70 \times 70 \times$ $46 \mathrm{~cm}$ ) linked together by two openings. Twelve objects, chosen from a large variety of items, were placed in each double cage and changed daily. Isolated rats were rehoused in fresh metal cages $(30 \times 20 \times 20 \mathrm{~cm})$ with sawdust bedding. Food and water were supplied ad lib to all rats, except during radial maze testing. All rats were differentially housed for $\mathbf{4 0}$ days (i.e., 26-66 days of age), after which they were housed in individual metal cages for the remainder of the experiment. Lights were on between $0700 \mathrm{~h}$ and $1900 \mathrm{~h}$, and the temperature was maintained at approximately $23^{\circ} \mathrm{C}$. All behavioral testing was conducted between $0900 \mathrm{~h}$ and 1800 h ("lights-on" period).

\section{Behavioral Tests}

The rats were tested for open-field activity at 70 days of age (46 days postsurgery), for spontaneous alternation at 73 days of age (49 days postsurgery), and for radial maze performance at 84 days of age ( 60 days postsurgery). For all tests, the rats were observed in one of two identical sets of apparatus; above each was a $40-\mathrm{W}$ white light mounted on the ceiling and shaded to provide even illumination. All testing was conducted blind.
Open field. The rats were tested in a $65 \times 65 \times 43.5 \mathrm{~cm}$ high open field consisting of unpainted wood walls with a white wooden floor marked into $2513 \times 13 \mathrm{~cm}$ squares. The open field was located on the floor of the testing room and was covered with a clear Perspex roof. After the rat was gently lowered into a corner of the open field, it was observed for a 6-min period and its behavioral measures were recorded for the first (0-2 $\mathrm{min})$ and last (4-6 $\mathrm{min})$ 2-min samples of each 6-min trial.

Spontaneous alternation. The apparatus was a gray Perspex T-maze (10 $\mathrm{cm}$ high $\times 10 \mathrm{~cm}$ wide) covered with a clear Perspex roof, and elevated $50 \mathrm{~cm}$ above floor level. The stem was $45 \mathrm{~cm}$ long, the goal arms were $19.5 \mathrm{~cm}$ long, and the $20-\mathrm{cm}$-long startbox and goalboxes were interchangeable. Gray Perspex guillotine doors placed $4.5 \mathrm{~cm}$ along the goal arm were used to retain the rat in the chosen arm. Once the rat had entered a goal arm on the first trial of each test (four paws past the guillotine door), it was retained there for $20 \mathrm{sec}$ before the goalbox, with the rat inside, was interchanged with the startbox for the second trial of the test. Percentage alternation was based on six tests, given at the rate of two per day. The second test each day was conducted approximately $4 \mathrm{~h}$ later, after all rats had completed the first test.

Radial maze testing. Radial maze performance was examined in a wooden radial maze that was elevated $66 \mathrm{~cm}$ above the floor. The gray maze consisted of a $30-\mathrm{cm}$-diam central platform from which radiated eight arms $(60 \mathrm{~cm}$ long $\times 10 \mathrm{~cm}$ wide) that were bordered by a 2.5 -cm-high piece of wood and separated from each other at the central platform by $16 \times 15 \mathrm{~cm}$ high walls. A 2-cmdiam, 1-cm-deep food well was located $1 \mathrm{~cm}$ from the end of each arm. At the end of spontaneous alternation testing, the rats were placed on a food-deprivation schedule to reduce their body weights to $80 \%$ of free-feeding weights. During this time, the rats underwent 5 days of pretraining in the maze. First, the rats were placed in the maze in groups of 5 for $10 \mathrm{~min}$ on 2 consecutive days; then they were placed in the maze singly for $4 \mathrm{~min}$ per day. During this pretraining period, each food well was filled with 30-40 reward pellets (Noyes $45 \mathrm{mg}$ ). Thereafter, the rats were tested individually in the maze for 10 daily trials in which all eight arms were baited with one reward pellet each at the beginning of each trial. A trial was terminated when the rat had eaten all eight rewards or when $10 \mathrm{~min}$ had elapsed. Reentries to arms were counted as errors if the reward had been eaten on a previous visit.

\section{Histological Procedures}

At the end of the experiment, the rats were sacrificed with an overdose of Nembutal, and their brains were removed and stored in $10 \%$ Formalin. Frozen sections, $52 \mu$ thick, were cut and used to make enlarged photomicrographs $(\times 8)$ to evaluate the locus and extent of the lesions.

\section{RESULTS}

\section{Histology}

The septal lesions in the rats from the two housing conditions were similar with little or no extraseptal damage (Figure 1). In all rats, there was extensive damage to the medial septum and mediodorsal septum anterior to the level of the body of the anterior commissure. Midline damage to the anterior ventral septum was present in 4 ISep and 6 ESep rats. Damage to the lateral septum was present in all cases, except for the ESep rat that had only minimal damage. The damage to the lateral septum was unilateral in 3 ISep and 2 ESep rats, bilaterally partial in 2 ISep and 4 ESep rats, and extensive, though not total, in 3 ISep and 3 ESep rats. Analysis using Spearman's rho, 




Figure 1. Coronal representations of minimum (black) and maximum (hatched) sizes of lesions found in isolated and enriched subgroups. however, showed no relationship between lesion size and behavioral performance on any task.

\section{Open-Field Activity (70 Days of Age)}

Figure 2 summarizes the open-field data. There was no housing main effect $(F<1.0)$, and rats with septal lesions showed higher ambulation than did sham-operated rats $[F(1,32)=14.28, p<.001]$ irrespective of housing conditions (housing $\times$ lesion, $F<1.0$ ). The only other significant effect involving housing or lesion was a housing $\times$ day $\times$ sample interaction $[F(2,64)=6.53$, $p<.005$ ), which we interpret to be due mainly to enriched rats' showing a greater within-trial decline in ambulation on the first 2 days (trials) and isolates showing a greater decline in ambulation on the 3rd day. The only clear effect to emerge from the analysis of the number
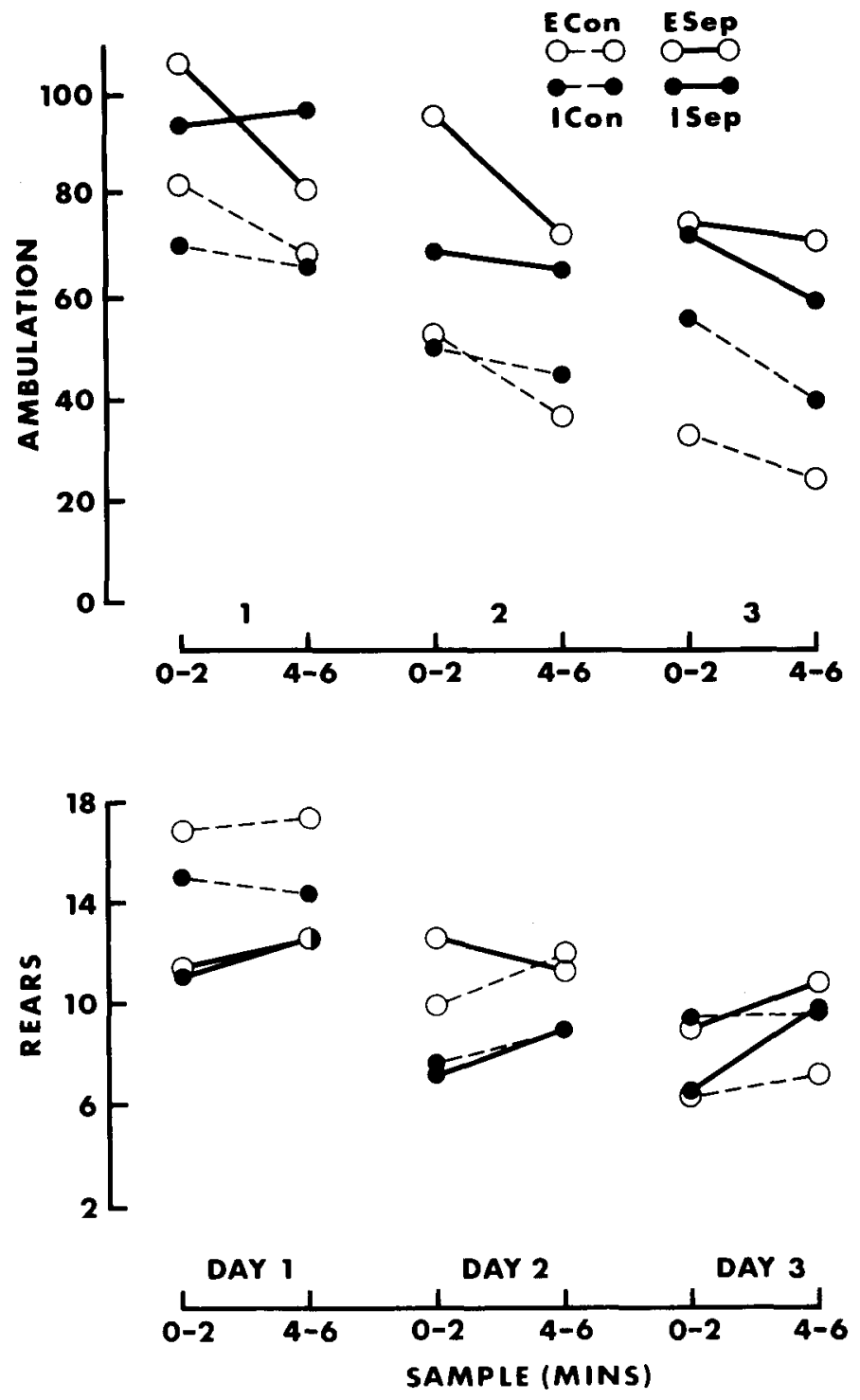

Figure 2. Mean ambulation (upper panel) and number of rears (lower panel) made in the open field. $E$ = postoperatively enriched; $I$ = postoperatively isolated; Con $=$ control rats; $\operatorname{Sep}=$ septal rats. 
of rears in the open field was a lesion $x$ day interaction $[F(2,64)=6.03, p<.005]$ resulting from the fact that septal rats made fewer rears than control rats only on the first day of testing.

\section{Spontaneous Alternation (73 Days of Age)}

Compared with sham-operated rats, rats with septal lesions were clearly impaired on the spontaneous alternation task $[F(1,32)=18.60, p<.001]$. One ISep and 3 ESep rats showed perseveration (scores of 0 or 1); 6 ISep and 6 ESep rats had scores of 2, 3, or 4; and 1 ISep rat showed alternation (score of 5). Postoperative differential housing had no effect on either control rats or rats with lesions (Table 1).

\section{Radial Maze Test (84 Days of Age)}

This test revealed a severe deficit in the performance of septal rats, which made a large number of errors $[F(1,32)=78.74, p<.001]$ and committed their first errors after an average of only 4-5 visits. Control rats, on the other hand, committed their first errors after about $6-7$ visits, if they made any at all $[F(1,32)=5.67, p<$ .01 ; see Figure 3].

The impairment shown by septal rats was clear in both lesion subgroups but, surprisingly, although ECon rats showed performance superior to that of ICon rats, ESep rats showed performance inferior to that of ISep rats. As a result, there were significant housing $\times$ lesion interactions for both total errors $[F(1,32)=6.17, p<.02]$ and number of visits before the first error $[F(1,32)=6.02, p<.02]$. Newman-Keuls tests showed that all subgroups differed from one another on both measures ( $p<.01$ in all cases). Inspection of individual error scores for septal rats revealed that 7 of the $9 \mathrm{ESep}$ rats showed consistently impaired performance, whereas the remaining 2 ESep rats (including the one with the largest lesion) showed some improvement across trials. Three of the 8 ISep rats showed some improvement across trials and 2 of the other 5 ISep rats (including the one with the largest lesion) showed errorless performances intermingled with a few trials on which they made several errors. The remaining finding for the first test was a lesion $\times$ trial interaction for the number of visits made before the first error $[F(9,288)=1.92, p<.05]$ The latter interaction resulted from the fact that, on average, septal rats showed some slow improvement in their ability to select different arms at the beginning of each trial.

Table 1

Mean Percentage of Spontaneous Alternation (fiSEM) in Septal and Control Rats Housed Postoperatively in Different Environments

\begin{tabular}{lccccc}
\hline & \multicolumn{2}{c}{ Septal } & & \multicolumn{2}{c}{ Control } \\
\cline { 2 - 3 } \cline { 5 - 6 } & $\%$ & $S E M$ & & $\%$ & $S E M$ \\
\hline Enriched & 38.8 & 8.8 & & 76.0 & 7.4 \\
Isolated & 43.6 & 8.9 & & 75.0 & 6.7 \\
\hline
\end{tabular}

Note-Lesion effect, $p<.001$; housing effect and housing $\times$ lesion interaction, not significant.
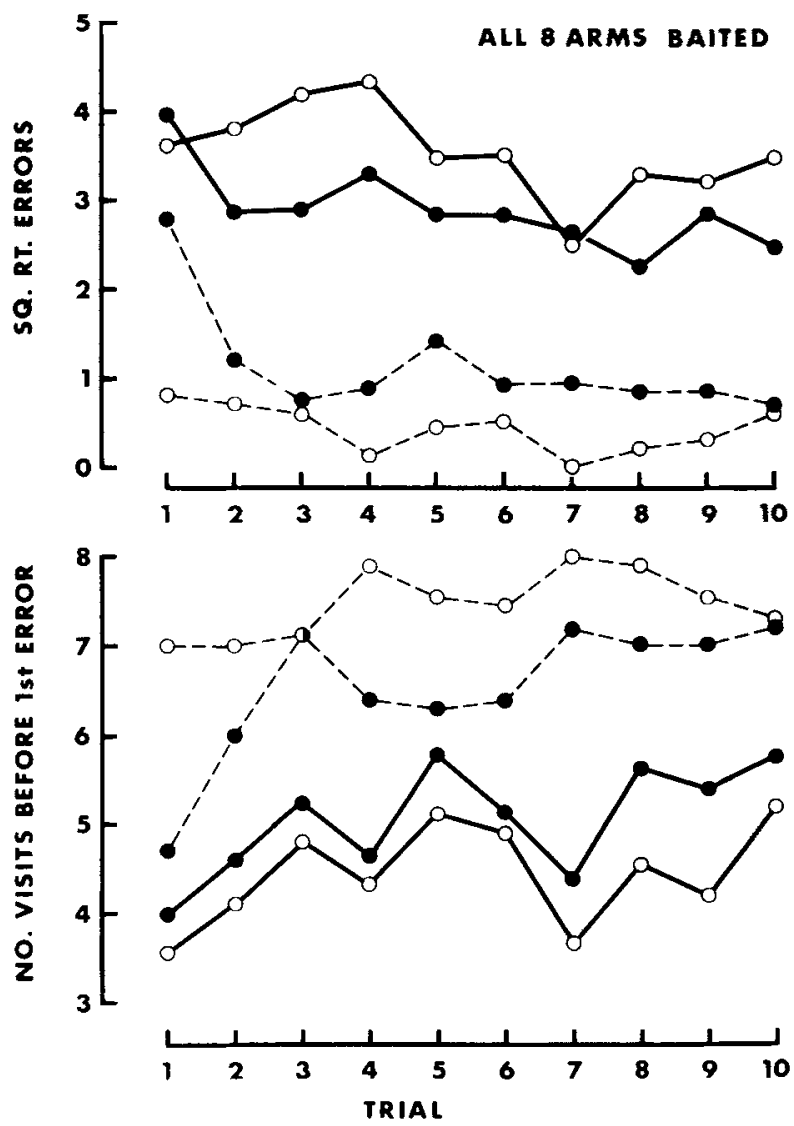

Figure 3. Errors (upper panel) and number of visits before committing the first error (lower panel) in the eight-arm radial maze when all arms were baited. Open circles = enriched groups; filled circles = isolated groups; broken lines = control groups; unbroken lines $=$ septal groups.

\section{DISCUSSION}

In agreement with previous work (e.g., DalrympleAlford, Kelche, Eclancher, \& Will, in press; Pallage, Toniolo, Will, \& Hefti, 1986), septal lesions increased ambulation and reduced rearing in the open field, impaired spontaneous alternation, and impaired performance in the radial maze. We found no evidence, however, that recovery in an enriched environment would ameliorate the behavioral deficits produced by septal lesions. Consistent with previous work on differential rearing (Einon, 1980; Einon et al., 1980; Juraska, Henderson, \& Muller, 1984; Kelche et al., 1987), we found that isolation of intact rats impaired their performance in the radial maze. In contrast, postoperative enrichment of septal rats exacerbated the lesion-induced deficit on the radial maze task. Although the finding of an inverse effect of postoperative enrichment on intact rats and rats with lesions is similar to that of a previous study on the effects of fimbria-fornix lesions on radial maze learning (Kelche et al., 1987), the present experiment showed that this exacerbation of the effects of septal lesions in enriched rats does not extend to other tasks. Moreover, the addition of a further eight 
trials of radial maze testing, but with only five of the eight arms baited, revealed that septal rats continued to make a high number of reentries to all arms, but that enriched septals were no longer any worse than isolated septals.

The present results contrast sharply with earlier work in which postoperative enrichment was found to ameliorate several of the deficits caused by dorsal hippocampus lesions (Dalrymple-Alford \& Kelche, 1985). They also contrast with previous reports that some of the behavioral effects of septal lesions are greater in isolated than in socially housed rats (see the introduction). Many variables, such as the specific tasks and measures employed, the age at lesion, and the size and extent of the lesions, may have contributed to these discrepancies, but the present data clearly demonstrate that postoperative enrichment does not always facilitate behavioral recovery in rats with septal lesions. One possible explanation for this is based on the idea that enrichment may have both direct and indirect effects on the septohippocampal system (DalrympleAlford \& Benton, 1984; Einon et al., 1980). Will et al. (1981) suggested that the entorhinal cortex might be a critical site for the beneficial effects on enrichment, since these effects were absent after large entorhinal-cortex lesions. Sharp, McNaughton, and Barnes (1983) reported that environmental enrichment led to a $48 \%$ increase in the extracellular population spike in the dentate gyrus in response to a single shock in the perforant path. This finding supports the idea that one indirect route for the effects of differential housing is via the entorhinal cortex, which provides the extrinsic connections between the hippocampus and neocortical structures. To accommodate the beneficial effects of enrichment after dorsal-hippocampus lesions, one must assume that the lesions are subtotal, and that this permits a putative influence of enrichment on the entorhinal cortex and the remaining hippocampal formation to achieve control over behavior through the output pathways in the intact fimbria-fornix. This assumption is consistent with the finding that enrichment fails to ameliorate the effects of fimbria-fornix lesions (Kelche et al., 1987). The septal lesions used here, however, disrupted the major subcortical inputs to the hippocampal formation but left intact the hippocampal system afferents that course the fornix columns. Therefore, the impaired radial maze performance of enriched rats with fimbria-fornix lesions may have been due to the disruption of hippocampal afferents from and/or running through the septal region. More work is needed to clarify the nature of this issue.

The specificity of the negative effects of enrichment on radial maze learning in septal rats makes it unlikely that differences in emotionality or arousal could account for the observed housing effects. Even when emotionality differences have been observed, they have not been related to behavior on other tasks. Lewis (1975) reported that preoperatively enriched rats with large bilateral lesions of the hippocampus were hyperactive longer than were isolated counterparts, but that both groups performed poorly on spatial reversal and extinction tasks. These considerations, along with Will, Rosenzweig, and Bennett's (1976) report that larger environmental effects were found with smaller cortical lesions, all point to the possibility that beneficial effects of enrichment are found only after partial bilateral or unilateral (e.g., Whishaw, Sutherland, Kolb, \& Becker, 1986) brain damage. The significance of this is that enriched rats might make better use of any remaining undamaged tissue (Finger, 1978), but the complexity of the findings presently available suggests that researchers should abandon any simple assumption that enrichment generally attenuates the symptoms induced by brain damage. It is becoming increasingly unlikely that any single explanation will adequately account for the diverse effects of differential housing in brain-damaged animals.

\section{REFERENCES}

AhMAD, S. S., \& HARVEY, J. A. (1968). Long-term effects of septal lesions and social experience on shock-elicited fighting in rats. Journal of Comparative \& Physiological Psychology, 66, 596-602.

Albert, D. J., WAlsh, M. L. , \& LoNGLY, M. (1985). Group-rearing abolishes hyperdefensiveness induced in weanling rats by lateral septal or medial accumbens lesions but not by medial hypothalamic lesions. Behavioral \& Neural Biology, 44, 101-109.

Dalrymple-Alford, J. C., \& Benton, D. (1984). Preoperative differential housing and dorsal hippocampal lesions in rats. Behavioral Neuroscience, 98, 23-34.

Dalrymple-Alford, J. C., \& Kelche, C. R. (1985). Behavioral effects of preoperative and postoperative differential housing in rats with brain lesions: A review. In B. E. Will, P. Schmitt, \& J. C. DalrympleAlford (Eds.), Brain plasticity, learning, and memory (pp. 441-458). New York: Plenum Press.

Dalrymple-Alford, J. C., Kelche, C., Eclancher, F., \& Will, B. (in press). Preoperative differential housing and behavioral recovery in rats with septal lesions. Behavioral \& Neural Biology.

EClancher, F., \& KarLI, P. (1979). Septal damage in infant and adult rats: Effects on activity, emotionality and muricide. Aggressive Behavior, 5, 388-415.

ECLANCHER, F., \& KARLI, P. (1981). Influence of rearing conditions on the acquisition of two-way active avoidance responses by rats septalectomised at an early age. Behavioral Brain Research, 3, 83-98.

EINON, D. (1980). Spatial memory and response strategies in rats: Age, sex and rearing differences in performance. Quarterly Joumal of Experimental Psychology, 32, 473-489.

Einon, D. F., Morgan, M. J., \& Will, B. E. (1980). Effects of postoperative environment on recovery from dorsal hippocampal lesions in young rats: Tests of spatial memory and motor transfer. Quarterly Journal of Experimental Psychology, 32, 137-148.

Fass, B. K., Wrege, K., Greenough, W. T., \& Stein, D. G. (1980). Behavioral symptoms following serial or simultaneous septal-forebrain lesions: Similar syndromes. Physiology \& Behavior, 25, 683-690.

FINGER, S. (1978). Environmental attenuation of brain-lesion symptoms. In S. Finger (Ed.), Recovery from brain damage: Research and theory (pp. 297-329). New York: Plenum Press.

Finger, S., \& Stein, D. G. (1982). Brain damage and recovery of function: Research and clinical perspectives. New York: Academic Press.

Johnson, D. A., Spiker, M., \& Carlson, K. (1984). Open field social behavior in rats as a function of septal lesions in infancy and group versus isolated rearing conditions. Physiological Psychology, 12, 14-16.

Juraska, J. M., Henderson, C., \& Muller, J. (1984). Differential rearing experience, gender, and radial maze performance. Developmental Psychobiology, 17, 209-215. 
Kelche, C., Dalrymple-Alford, J., \& Will, B. (1987). Effects of postoperative environment on functional recovery after fimbria-fornix transection in the rat. Physiology \& Behavior, 40, No. 6.

Kelche, C. R., \& WiLl, B. E. (1978). Effets de l'environnement sur la restauration fonctionnelle après lésions hippocampiques chez des rats adultes. Physiology \& Behavior, 21, 935-942.

LEWIS, M. E. (1975). The influence of early experience on the effects of one-and two-stage hippocampal lesions in male rats. Unpublished master's thesis, Clark University, Worcester, MA.

Pallage, V., Toniolo, G., Will, B., \& Hefti, F. (1986). Long-term effects of nerve growth factor and neural transplants on behavior of rats with medial septal lesions. Brain Research, 386, 197-208.

Rosenzweig, M. R., \& BenNETT, E. L. (1969). Effects of differential environments on brain weights and enzyme activities in gerbils, rats and mice. Developmental Psychobiology, 2, 87-95.

Sharp, P. E., McNaughton, B. L., \& BarNes, C. A. (1983). Spontaneous synaptic enhancement in hippocampi of rats exposed to a spatially complex environment. Society for Neuroscience Abstracts, 9 , 647.

Whishaw, I. Q., Sutherland, R. J., Kolb, B., \& Becker, J. B. (1986). Effects of neonatal forebrain noradrenaline depletion on recovery from brain damage: Performance on a spatial navigation task as a function of age of surgery and postsurgical housing. Behavioral \& Neural Biology, 46, 285-307.
Will, B. E., Deluzarche, F., \& Kelche, C. R. (1983). Does postoperative environment attenuate or exacerbate symptoms which follow hippocampal lesions in rats? Behavioral Brain Research, 7, 125-132.

Will, B. E., \& ECLANChER, F. (1984). Early brain damage and early environment. In C. R. Almli \& S. Finger (Eds.), Early brain damage (Vol. 2, pp. 349-367). New York: Academic Press.

WiLL, B. E., \& KelChe, C. R. (1979). Effects of different postoperative environments on the avoidance behavior of rats with hippocampal lesions: Recovery or improvement of function? Behavioral \& Neural Biology, 27, 96-106.

Will, B. E., Kelche, C. R., \& Deluzarche, F. (1981). Effects of postoperative environment on functional recovery after entorhinal cortex lesions in the rat. Behavioral \& Neural Biology, 33, 303-316.

Will, B. E., RosenZWEIG, M. R., \& BeNNETT, E. L. (1976). Effects of differential environments on recovery from neonatal brain lesions, measured by problem-solving scores and brain dimensions. Physiology \& Behavior, 16, 603-611.

(Manuscript received October 15, 1986; revision accepted for publication August $5,1987$. ) 